\title{
No red cell alloimmunization or change of clinical outcome after using fresh frozen cancellous allograft bone for acetabular reconstruction in revision hip arthroplasty: a follow up study
}

Falk Mittag ${ }^{1}$, Matthias Straub ${ }^{1}$, Richard Schäfer ${ }^{2}$, Torsten Kluba ${ }^{1 *}$ and Ingmar Ipach ${ }^{1}$

\begin{abstract}
Background: Possible immunization to blood group or other antigens and subsequent inhibition of remodeling or incorporation after use of untreated human bone allograft was described previously. This study presents the immunological, clinical and radiological results of 30 patients with acetabular revisions using fresh frozen non-irradiated bone allograft.

Methods: ABO-incompatible (donor-recipient) bone transplantation was performed in 22 cases, Rh(D) incompatible transplantation in 6 cases. The mean follow up of 23 months included measuring Harris hip score and radiological examination with evaluation of remodeling of the bone graft, implant migration and heterotopic ossification. In addition, all patients were screened for alloimmunization to Rh blood group antigens.

Results: Compared to the whole study group, there were no differences in clinical or radiological measurements for the groups with ABO- or Rh(D)-incompatible bone transplantation. The mean Harris Hip Score was 80.6. X-rays confirmed total remodeling of all allografts with no acetabular loosening. At follow up, blood tests revealed no alloimmunization to Rh blood group donor antigens.

Conclusions: The use of fresh frozen non-irradiated bone allograft in acetabular revision is a reliable supplement to reconstruction. The risk of alloimmunization to donor-blood group antigens after ABO- or Rh-incompatible allograft transplantation with a negative long-term influence on bone-remodeling or the clinical outcome is negligible.
\end{abstract}

Keywords: Acetabular revision, Allograft bone, Remodeling, Alloimmunization, ABO, Rhesus

\section{Background}

Aseptic loosening is the most common long-term complication in total hip arthroplasty. Revision of the failed acetabular component remains challenging due to migration of the implant during loosening and procedures to remove the primary implant often result in an extensive loss of pelvic bone. Bone grafting combined with insertion of a revision acetabular component is an established method to restore pelvic bone stock [1-4]. Because of its limited availability and poor quality in elderly patients the use of an autogenous graft is often not

\footnotetext{
* Correspondence: torsten.kluba@med.uni-tuebingen.de

'Department of Orthopaedic Surgery, University Hospital Tuebingen,

Hoppe-Seyler-Str 3, Tuebingen 72076, Germany

Full list of author information is available at the end of the article
}

feasible. Therefore, allografts are utilized in most acetabular revisions. Regardless of whether treated (chemical, freeze dried, irradiated) or fresh-frozen non-irradiated allografts are used, the clinical outcome is usually good [5-7]. We have been using fresh frozen untreated allografts from our own bone bank in revision acetabular hip arthroplasty for decades with good results. Nevertheless, immunization to blood group antigens or other antigens and subsequent possible inhibition of long-term remodeling or incorporation of the transplanted bone is mentioned as an argument against the use of fresh frozen non-irradiated allografts $[8,9]$.

The purpose of this study was to evaluate whether allografting of ABO- and Rh-incompatible patients (donor-recipient) leads to recipient-alloimmunization 
with proof of irregular erythrocyte antibodies (Rh system). In addition, clinical and radiological findings should be observed in the postoperative course.

\section{Methods \\ Graft extraction}

Femoral head bone grafts were obtained from donors through total hip arthroplasty. The grafts were not treated, immediately double packed and stored at $-80^{\circ} \mathrm{C}$ at our local bone bank. Besides blood group determination (AB0 and Rhesus) donors were screened for infectious diseases (HIV, Hepatitis B and -C, Syphilis) before and at least six weeks after surgery according to the local guidelines for operating a bone bank.

\section{Patients}

We retrospectively reviewed 30 patients (13 males, 17 females). The study was performed in compliance with the Helsinki Declaration and approved by the local Ethics Committee (Nr. 254/2010BO2, University Tuebingen, Germany). Between 2006 and 2010 all included patients received fresh frozen cancellous allograft bone from our bone bank during acetabular revision at our institution by the corresponding author (T.K.). Acetabular defects were determined from preoperative radiographs and the intraoperative assessment using the classification introduced by Paprosky et al. [10]. Type I defects were present in 8 hips (26.7\%), type II A in 9 (30\%), type II B in 3 (10\%), type II C in 3 (10\%), type III A in 2 (6.7\%), type III B in $3(10 \%)$ and type IV with complete pelvic discontinuity in 2 (6.7\%). The amount of impacted bone material was determined by the size of the defect. ABO incompatible (donor-recipient) bone transplantation was performed in 22 cases. $6 \mathrm{Rh}(\mathrm{D})$ negative patients received bone from $\mathrm{Rh}(\mathrm{D})$ positive patients. In most cases, revision components were implanted (BurchSchneider reinforcement ring or Mueller ring, Zimmer $\mathrm{GmbH}$, Switzerland) for acetabular reconstruction. The average age at the time of surgery was 71 years (range 48 to 90$)$.

\section{Follow up}

All patients were screened for alloimmunization to $\mathrm{Rh}$ blood group antigens (D, C, c, E, e) with a minimum clinical and radiographic follow-up of 6 months (mean 23 months). We did not screen for further blood group antigens.

Clinical assessments were evaluated according to the criteria of the Harris Hip Score including scoring of pain, walking and mobility of the revised hip [11].

Radiological evaluation was performed after 7 days, 6 weeks and at the time of study-related follow up at least 6 months after surgery. The acetabular index and horizontal and vertical migration of the acetabular component were measured [12]. Acetabular component loosening was defined if the sum of horizontal and vertical migration was $\geq 5 \mathrm{~mm}$, if the change in the acetabular index was $\geq 5^{\circ}$ or if there was a progressive radiolucent line $\geq 1 \mathrm{~mm}$ around the whole acetabular component [13]. The Brooker-classification was used for determination of heterotopic ossification [14]. Remodeling of the allograft was measured on the basis of appearance of trabecular remodeling within the graft.

Table 1 Study groups

\begin{tabular}{|c|c|c|c|}
\hline & AB0-incompatible transplantation & Rh(D)-incompatible transplantation* & All patients \\
\hline Number of patients (hips) & 22 & 6 & 30 \\
\hline Gender (male:female) & $8: 14$ & $1: 5$ & $13: 17$ \\
\hline Mean age in years (range) & $71(48$ to 90$)$ & $66(52$ to 78$)$ & 71 (48 to 90$)$ \\
\hline \multicolumn{4}{|l|}{ Acetabular revision component (number of hips) } \\
\hline Burch-Schneider ring & 7 & 1 & 11 \\
\hline Müller ring & 13 & 4 & 15 \\
\hline Standard cup & 2 & 1 & 4 \\
\hline Mean follow up in month (range) & $21(6$ to 55$)$ & $28(14$ to 38$)$ & $23(6$ to 63$)$ \\
\hline \multicolumn{4}{|l|}{ Follow up } \\
\hline Alloantibodies to donor (Rh system**) & none & none & none \\
\hline Mean Harris Hip Score (range) & 79.5 (53 to 100$)$ & 86.3 (72 to 100$)$ & 80.6 (43 to 100$)$ \\
\hline Acetabular component tilting in ${ }^{\circ}$ (range) & $1.37(0.1$ to 3.3$)$ & $1.00(0.5$ to 2.1$)$ & $1.29(0$ to 4,4$)$ \\
\hline Horizontal migration in mm (range) & $2.17(0.1$ to 6.0$)$ & $2,27(1.5$ to 3.4$)$ & $2,01(0.1$ to 4.5$)$ \\
\hline Vertical migration in mm (range) & 1.27 (0 to 4.2$)$ & $1.13(0$ to 2.1$)$ & $1,44$ (0 to 4.2$)$ \\
\hline Graft remodeling rate (\%) & 100 & 100 & 100 \\
\hline
\end{tabular}

* $R h(D)$-negative patients received bone from $R h(D)$-positive donors.

** Screening for antibodies against 5 Rhesus antigens (D, C, C, E, e). 


\section{Statistical analysis}

The paired $t$-test and Pearson's chi square test were used for intra-group analysis. The Pearson correlation coefficient was calculated to measure the dependence between the different variables. A p-value $\leq 0.05$ was considered significant.

\section{Results}

\section{Alloimmunization}

AB0 incompatible (donor-recipient) allograft transplantation was performed in 22 cases, Rhesus(D)-incompatible transplantation in 6 of 30 cases. No antibodies to donor blood-antigens were found in any patient in the Rhesussystem (Dd, Cc, Ee) during follow up. Especially Rh(D) incompatible transplantation did not lead to a detectable alloimmunization. We also found no differences in clinical or radiological measurements for these groups (Table 1).

\section{Clinical and radiological findings}

The revision rate of the entire study group of 30 patients was $3.3 \%$ due to a superficial septic complication in one patient after an AB0- and Rh-compatible allograft transplantation. All 30 acetabular components were still in place at time of follow up. The mean Harris-Hip-Score at the latest follow up was 80.6 points (range 43 to 100). Significant acetabular component tilting $>5^{\circ}$ (range $0^{\circ}$ to $\left.4.4^{\circ}\right)$, horizontal migration $\geq 5 \mathrm{~mm}(0.1$ to $6.0 \mathrm{~mm})$ or vertical migration $\geq 5 \mathrm{~mm}$ (0 to $4.2 \mathrm{~mm}$ ) was found in one case. All allografts remodeled with homogeneous trabeculation and no radiolucent lines at the hostallograft interface (Figure 1). Periacetabular heterotopic ossification was found in 6 cases (20\%): 5 patients with grade II and 1 patient with grade III. However, in 5 of 6 cases, preoperative radiographs revealed heterotopic ossification of a similar grade. There was no correlation between increasing preoperative acetabular defects and Harris Hip Score at follow up $(\mathrm{p}=0.46)$. Advanced age was negatively correlated with the Harris Hip Score, but did not reach statistical significance $(R=-0.51, p=0.21)$.

\section{Discussion}

The best method of preparation and processing of bone allografts is still under discussion. We use fresh frozen allografts in our department with no further chemical or physical processing. The use of fresh frozen allografts became subject to the restrictive European Union Directive due to the concern of a possible transmission of an infectious disease or other illness [15]. A low risk of disease transmission remains in some cases which are described in the literature [16,17]. Sufficient donorscreening is therefore essential. Except for Rh(D)-negative females of childbearing age, fresh frozen allografts are commonly transplanted AB0- and Rh-incompatible.

In the present study we found no alloimmunization in $\mathrm{Rh}(\mathrm{D})$-incompatible transplanted recipients. With respect to other clinically relevant antigens in the Rh system $(\mathrm{C}, \mathrm{c}$, $\mathrm{E}, \mathrm{e})$ no irregular antibodies could be detected in the recipients after transplantation. However, reviewing the literature, there are some rare cases of $\mathrm{Rh}(\mathrm{D})$-alloimmunisation after bone grafting $[18,19]$.

Concerning the AB0 system, the human body always naturally contains antibodies against the other blood group antigens (except genotype $\mathrm{AB}$ ). Therefore, the detection of anti-A or anti-B alloantibodies cannot be regarded as proof of a possible alloimmunization after AB0 incompatible transplantation. However, AB0 incompatible transplantation might cause an increase of the anti-A or Anti-B titer (boostering) [20]. Due to the retrospective design of our study, we could not investigate a possible boostering of anti-A or Anti-B alloantibodies after AB0-incompatible transplantation of bones.
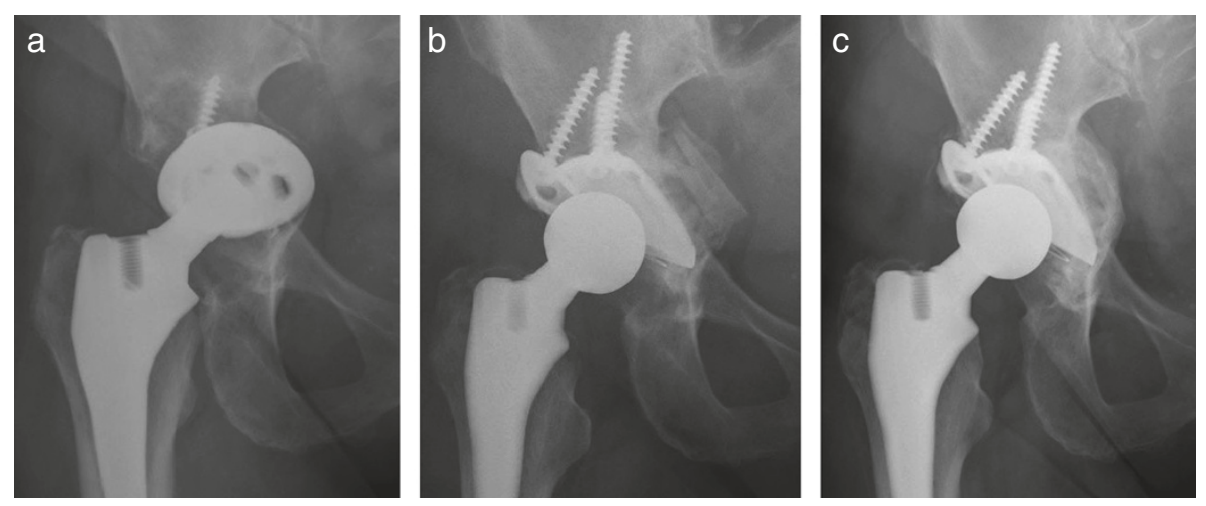

Figure 1 a. Preoperative anteroposterior radiograph of a 72 year old woman, 13 years after total hip replacement, showing aseptic loosening of the acetabular component with migration into the small pelvis (type III B). b. 7 days after acetabular revision using a Mueller ring and fresh frozen non-irradiated allograft bone. Note the distinguishable allograft bone chips medial of the ring. A polyethylene cup was cemented into the ring. c. 28-month follow up radiograph showing the implants to be unchanged with complete remodeling of the allograft bone and homogeneous trabeculation. 
Stassen et al. found no irregular antibodies in patients before and after transplantation of frozen allogeneic bone in orthopaedic or maxillo-facial surgery [21].

Despite the fact that we found no antibodies and according to the current standards, we still recommend transplanting only $R h(D)$-negative bones to $R h(D)$-negative women of childbearing age. For all other patients, our study confirms that blood-group compatible transplantation of fresh frozen allografts is not necessary in revision hip arthroplasty.

To minimize the risks of infection, allografts could be sterilized by irradiation and chemical or physical treatment. This treatment could result in a destruction of the bone matrix and subsequent reduction in strength affecting long-term graft incorporation [22]. Despite this consideration, studies show good mid- and longterm results of treated bone grafts in revision hip arthroplasty [1-7,23-26].

Our study revealed $100 \%$ graft remodeling and only one case of significant acetabular component migration (6 mm migration with no clinical symptoms, no surgical revision necessary) at a mean follow up of 23 months. We found radiological evidence of good allograft trabeculation as a sign of complete remodeling and integration into the recipient bone structure, even after 6 months. This rapid remodeling rate has also been demonstrated in several other studies [23,24]. We have to consider, that complete remodeling does not mean complete incorporation of the graft. This could only be confirmed by biopsy and histological examination.

Acetabular reconstruction using a revision implant and allograft bone for reconstructing pelvic bone stock is a reliable method of managing acetabular defects. The question remains whether to use treated or untreated allografts in hip revision surgery as both show good clinical results. Advantages of untreated fresh frozen non-irradiated allografts are their cost effectiveness, supposed better biological quality and availability in a local bone bank. A disadvantage is the slightly increased risk of disease transmission which can be minimized by sufficient donor-screening and sterile handling.

\section{Conclusions}

We conclude that the risk of alloimmunization against blood group antigens after ABO- or Rh-incompatible transplantation of bone with an influence on bone-remodeling or the clinical outcome is very low.

\section{Competing interests}

The authors declare that they have no competing interests.

\section{Authors' contributions}

Each author has made substantive intellectual contributions to this study:

FM: participated in collecting data and study design, drafted the manuscript. MS: participated in collecting data. RS: participated in study design

(immunologic research), manuscript revision. TK: participated in study design, performed the acetabular revisions, manuscript revision. IP: participated in study design, manuscript revision. All authors read and approved the final manuscript.

\section{Author details}

'Department of Orthopaedic Surgery, University Hospital Tuebingen, Hoppe-Seyler-Str 3, Tuebingen 72076, Germany. ${ }^{2}$ Institute of Clinical and Experimental Transfusion Medicine, University Hospital Tuebingen,

Otfried-Mueller-Str 4/1, Tuebingen 72076, Germany.

Received: 26 April 2012 Accepted: 11 September 2012

Published: 25 September 2012

\section{References}

1. Dua A, Kiram K, Malhotra R, Bhan S: Acetabutar reconstruction using fresh frozen bone allograft. Hip Int 2010, 20(2):143-149.

2. Kawanabe K, Akiyama H, Onishi E, Nakamura T: Revision total hip replacement using the Kerboull acetabular reinforcement device with morsellised or bulk graft: results at a mean follow-up of 8.7 years. J Bone Joint Surg Br 2007, 89(1):26-31.

3. Winter E, Piert M, Volkmann R, Maurer F, Eingartner C, Weise K, Weller S: Allogenic cancellous bone graft and a Burch-Schneider ring for acetabular reconstruction in revision hip arthroplasty. J Bone Joint Surg Am 2001, 83-A(6):862-867.

4. Lakemeier S, Aurand G, Timmesfeld N, Heyse TJ, Fuchs-Winkelmann S, Schofer MD: Results of the cementless Plasmacup in revision total hip arthroplasty: a retrospective study of 72 cases with an average follow-up of eight years. BMC Musculoskelet Disord 2010, 11:101.

5. Mehendale S, Learmonth ID, Smith EJ, Nedungayil S, Maheshwari R, Hassaballa MA: Use of irradiated bone graft for impaction grafting in acetabular revision surgery: a review of fifty consecutive cases. Hip Int 2009, 19(2):114-119.

6. Ochs BG, Schmid U, Rieth J, Ateschrang A, Weise K, Ochs U: Acetabular bone reconstruction in revision arthroplasty: a comparison of freezedried, irradiated and chemically-treated allograft vitalized with autologous marrow versus frozen non-irradiated allograft. J Bone Joint Surg Br 2008, 90(9):1164-1171.

7. Vargas B, Caton J: Acetabular revision with freeze-dried irradiated and chemically treated allograft: a minimum 5-year follow-up of 17 cases. Int Orthop 2009, 33(1):35-39.

8. Bos GD, Goldberg VM, Zika JM, Heiple KG, Powell AE: Immune responses of rats to frozen bone allografts. J bone Joint Surg Am 1983, 65(2):239-246.

9. Stevenson S, Horowitz M: The response to bone allografts. J Bone Joint Surg Am 1992, 74(6):939-950.

10. Paprosky WG, Perona PG, Lawrence JM: Acetabular defect classification and surgical reconstruction in revision arthroplasty. A 6-year follow-up evaluation. J Arthroplasty 1994, 9(1):33-44.

11. Harris WH: Traumatic arthritis of the hip after dislocation and acetabular fractures: treatment by mold arthroplasty. An end-result study using a new method of result evaluation. J Bone Joint Surgery Am 1969, 51(4):737-755

12. Peters $C L$, Curtain M, Samuelson KM: Acetabular revision with BurchSchneider antiprotrusio cage and cancellous allograft bone. J Arthroplasty 1995, 10:307-312.

13. DeLee JG, Charnley J: Radiological demarcation of cemented sockets in total hip replacement. Clin Orthop Relat Res 1976, 121:20-32.

14. Brooker AF, Bowerman JW, Robinson RA, Riley LH: Ectopic ossification following total hip replacement. Incidence and a method of classification. J Bone Joint Surg Am 1973, 55(8):1629-1632.

15. European Union (no authors listed): Directive 2004/23 of the European parliament and of the council of 31 March 2004 on setting standards of quality and safety for the donation, procurement, testing, processing, preservation, storage and distribution of human tissues and cells. J Eur Union 2004, 102:48-58.

16. Centers of disease Control: Transmission of HIV through bone transplantation: case report and public health recommendations. MMWR 1988, 37(39):597-599.

17. Schratt HE, Regel G, Kiesewetter B, Tscherne H: HIV infection caused by cold preserved bone transplants. Unfallchirurg 1996, 99(9):679-684.

18. Jensen TT: Rhesus immunization after bone allografting. A case report. Acta Orthop Scand 1987, 58(5):584. 
19. Musclow CE, Dietz G, Bell RS, Beaudry-Clouatre M: Alloimmunization by blood group antigens from bone allografts. Acta Orthop Scand 1993, 64(3):354-356.

20. Knaepler H, Ascherl R, Kretschmer V: Immunization against blood group antigens by allogenic bone transplantation. Chirurg 1990, 61(11):830-832

21. Stassen JG, van Dijk BA, van Horn JR, Kunst VA: No irregular erythrocyte antibodies observed after bone allografts in 144 patients. Acta Orthop scand 1993, 64(3):354-356.

22. Hamer AJ, Stockley I, Elson RA: Changes in allograft bone irradiated at different temperatures. J Bone Joint Surg Br 1999, 81 (2):342-344.

23. Pitto RP, Di Muria GY, Hohmann D: Impaction grafting and acetabular reinforcement in revision hip replacement. Int Orthop 1998, 22(3):161-164.

24. Schimmel JW, Buma P, Versleyen D, Huiskes R, Slooff TJ: Acetabular reconstruction with impacted morselized cancellous allografts in cemented hip arthroplasty: a histological and biomechanical study on the goat. J Arthroplasty 1998, 13(4):438-448.

25. Mathijssen NM, Petit PL, Pilot P, Schreurs BW, Buma P, Bloem RM: Impregnation of bone chips with antibiotics and storage of antibiotics at different temperatures: an in vitro study. BMC Musculoskelet Disord 2010, 11:96.

26. Mathijssen NM, Hannink G, Pilot P, Schreurs BW, Bloem RM, Buma P: Impregnation of bone chips with alendronate and cefazolin, combined with demineralized bone matrix: a bone chamber study in goats. BMC Musculoskelet Disord 2012, 13(1):44

doi:10.1186/1471-2474-13-187

Cite this article as: Mittag et al:: No red cell alloimmunization or change of clinical outcome after using fresh frozen cancellous allograft bone for acetabular reconstruction in revision hip arthroplasty: a follow up study. BMC Musculoskeletal Disorders 2012 13:187.

\section{Submit your next manuscript to BioMed Central and take full advantage of:}

- Convenient online submission

- Thorough peer review

- No space constraints or color figure charges

- Immediate publication on acceptance

- Inclusion in PubMed, CAS, Scopus and Google Scholar

- Research which is freely available for redistribution 